\title{
INDICADORES DO PADRÃO DE SONO EM CRIANÇAS DE 2 A 5 ANOS*
}

\section{SLEEP PATTERN INDICES AMONG 2 TO 5-YEAR OLD CHILDREN}

Ruth B. Lass ${ }^{1}$

Therezinha Moreira Leite ${ }^{2}$

LASS, R. B.; LEITE, T. M. Indicadores do Padrão de Sono em Crianças de 2 a 5 Anos. Rev. Bras. Cre c. Des. Hum., São Paulo, IV(2), 1994.

Resumo: Este trabalho refere dados obtidos por estudo exploratório com o objetivo de verificar características, do comportamento de sono em crianças, de uma perspectiva psicológica. Trata-se de dois grupos de 15 crianças, nível sócio-econômico médio e freqüentando a pré escola; um constituído de crianças de 2a. $6 \mathrm{~m}$. a 3a. 8m., g do sexo masculino, 7 do sexo feminino; outro, de crianças de 4a. 6m. a 5a. $6 \mathrm{~m}$., 7 do sexo masculino, 8 do sexo feminino. Questionários e entrevistas foram utilizados para obtenção de dados sobre seu comportamento de sono por parte das mães. Os dados sobre abandono da sesta, necessidade de companhia para adormecer, ocorrência e identificação de sonho, revelam tendências a serem apontadas. Alguns hábitos como: horário de dormir, abandono da sesta, utilização sistemática de objeto transicional, medo de escuro, solicitação de luz acesa, indicam fatores de ordem ps quica e social. Este trabalho expressa a tentativa de obter fndices de desenvolvimento do padrão de sono, tendo por referencial a prática psicológica especialmente clinica. Não tendo como perspectiva imediata os distúrbios de sono nos primeiros anos de vida, tenta indicar as características do estabelecimento desse padrão e suas relações com a vida de vigília.

Palavras-chave: padrão de sono, desenvolvimento infantil, fatores psicossociais, sono na criança.

Summary: This paper considers data obtained from an exploratory research with the objective of verifying sleep behaviour characteristics in children, from a psychological perspective. Two groups of 15 middle class children each were formed: one with 8 male and 7 female children between the ages of $2 \mathrm{y} .6 \mathrm{~m}$. and $3 \mathrm{y} .8 \mathrm{~m}$., and the other with 7 male and 8 female between the ages of $4 y .6 \mathrm{~m}$. and Sy. $6 \mathrm{~m}$.. Both groups attended nursery school. Children's mothers reported data through questionnaires and interviews about children's sleep behaviour. The relevant data referred to: abandoning the "sesta" (afterlunch nap); demanding adult presence to fall asleep; reporting the occurrence of dreams; differentiating and day dreaming from night dreams. Some habits as sleeping time, systematic utilization of a transitional object, fear of darkness and demanding lights on are related to psychic and social factors. Research projects about sleep pattern development seem relevant to evaluate sleeping behaviour. Emphasis is given more on psychological aspects than on descriptive ones. This paper reports a tentative research in order to obtain development sleep pattern indices in human beings having as referent the clinical practice. More than pointing, explaining and studying sleep disturbances in a child's early years, it aims at their genesis and their relation with insomnia, from a psychological perspective.

Key-words: sleep pattern, child development psychosocial factors, child sleep.

* Os dados desta pesquisa foram apresentados, em resumo, no 1I Congresso Brasileiro sobre o Sono, São Paulo, 14/10/1989, e no I Congresso ^Interno do Instituto de Psicologia da USP, 18-19/11/1991.

1 Psicóloga Clínica.

End.: Rua Desembargador Costa Carvalho 181, Curitiba - PR, CEP 80440-210.

2 Prof. Livre Docente do Departamento de Psicologia Clínica do Instituto de Psicologia da Universidade de São Paulo.

End.: Prof. Lúcio de Martins Rodrigues Trav. 5 Bloco 21 Cidade Universitária, São Paulo - SP, CEP 05508-900 Fone/Fax: (011) 818.4910 


\section{INTRODUÇ̃̃O}

Em nosso meio, onde pesquisas tendo por objetivo o estudo do desenvolvimento do padrão de sono têm sido raras, este estudo visou especialmente verificar índices no estabelecimento e desenvolvimento do padrão de sono no sujeito humano. Sendo esse seu enfoque específico, centra-se no aspecto evolutivo do sono em lugar de se ater à patologia ou aos distúrbios, com especial ênfase nas ocorrências do primeiro ano de vida, como se pode levantar na literatura sobre o sono na criança. Pretende ser levantamento preliminar, em dois grupos de crianças nas faixas de 2a. $6 \mathrm{~m}$. a 3a. $6 \mathrm{~m}$., e 4a. $6 \mathrm{~m}$. a Sa. $6 \mathrm{~m}$., cujo acesso foi facilitado pela frequência a uma pré-escola (com exceção de uma menina, de 2a. 1lm.).

Por outro lado, sem perder de vista a necessidade de proceder ao levantamento de índices adequados à definição e caracterização do que se convencionou chamar de distúrbios de sono na criança, pareceu-nos importante, num primeiro passo, levar em conta a complexidade de fatores atuando sobre o comportamento característico de sono nas várias faixas de idade, ainda que considerando as diferenças individuais. Vale ressaltar que o questionário elaborado para levantar dados a respeito do sono e seu desenvolvimento em crianças em geral, e nas crianças estudadas em particular, teve especialmente essa finalidade.

A matéria colocada dessa forma toma importância primordial, desde que os distúrbios de sono em idade precoce, na prática clínica e na literatura, têm sido tomados como os primeiros sinais de conflitos emocionais na criança (HOUZEL, 1972). Levantamentos entre crianças com distúrbios de sono revelam estarem os mesmos associados a distúrbios anteriores do ritmo vigília-sono; também, problemas de sono em vida ulterior parecem estar correlatos a distúrbios de sono em fases infantis (SALZARULO et ai, 1978; SALZARULO \& CHEVALER, 1983).

Levando esses falos em consideração, um enfoque ontogenético no estudo do sono poderá centrar-se em uma abordagem compreensiva de dados da anamnese, da relação no par mãe-criança (mãe e/ou substitutos, familiares ou outros) e da relação da criança com figuras e objetos representativos de seu ambiente; condições afetivoemocionais na construção da sua história/estória poderão ser pesquisadas; a conceituação e o lugar atribuído por parte dos pais especificamente ao sono e ao sonho, o reconhecimento de medidas educacionais utilizadas por eles, também as relativas ao estabelecimento e à manutenção do sono desde a idade a mais precoce na criança, poderão contribuir para o estudo do processo de aquisição do comportamento de sono.
Apresentamos neste trabalho alguns dados que nos parecem relevantes, obtidos a partir do método proposto e que se delineia abaixo. Ainda que em pequeno número de sujeitos, merecem atenção devido a aspectos básicos a respeito do tema e a tendências no grupo. Além disso, propositadamente teremos por foco questões concernentes à temática psicológica que os mesmos sugerem, assim como questões concernentes à relação da criança com o ambiente e, especialmente, em relação à figura dos pais.

Vale ressaltar, no entanto, a necessidade e a importancia de levantamentos que permitam tratamento em maior escala, como, por exemplo, relativo à ocorrência de falos específicos ao desenvolvimento do padrão de sono na população em geral ou na população atendida em clínica infantil. E, por outro lado, pesquisas sistemáticas que privilegiem o estudo do sujeito no seu desenvolvimento, tendo em vista variaveis de diversas ordens.

Diante da proposta que ora se apresenta, pensamos ser de interesse indicar aspectos básicos no desenvolvimento infantil referentes ao sono. No recém-nascido, o adormecimento processa-se, em geral, facilmente no curso do primeiro ano de vida; um padrão bastante estabelecido parece manter 0 ritmo sono-vigília, permanecendo o bebe em média de 17 a 18 horas em sono. Satisfação das necessidades básicas, especialmente a amamentação, tem sido citada como garantindo a continuidade no adormecimento e a manutenção do sono no bebê. No entanto, ressalta-se atualmente o papel dos ritmos biológicos na determinação dos períodos de sono e despertar da criança recém-nascida. Ademais fatores de diversas ordens como condições do sistema nervoso, aiternancia claro-escuro, ação ambiental e particularmente a qualidade das trocas afetivas, consubstanciam o estabelecimento e a manutenção do período de sono no sujeito humano (MAZET \& BRACONNIER, 1986).

Seguindo MAZET \& BRACONNIER (1986), diríamos que em idade posterior, muito especialmente conteúdos de ordem afetiva e emocional, devem ser levados em conta além desses fatores, nos comportamentos de sono. Nota-se, então, a oposição a ir dormir a partir dos 8-9 meses, correlata à fase de separação-individuação estendendo-se entre a idade de $6 \mathrm{~m}$. e a idade de 2a. e 6m.. Daí, a necessidade de objetos (animaizinhos de pelúcia, fronha, um simples pedaço de pano,...), sempre os mesmos, para promover 0 adormecimento da criança, e que tomam o valor de objetos transicionais na linguagem de W innicott. Rituais antecedendo ao adormecer, a partir dos 2 anos, e que se atenuam por volta dos 3-4 anos, estariam também explicados por angústias, aparentemente sem razão, em relação a objetos e pessoas, especialmente o pai e a mãe. Fobias podem ressurgir diante de condições circunstantes ao período do adormecer e do sono, por volta dos 3-4 anos. Pequenos sonhos em que se fantasiam 
a presença de animais, fantasmas e figuras aterrorizantes..., antecedendo ao sono, podem explicar condutas contrafóbicas, como a necessidade de luz acesa, porta aberta, presença de um adulto.

Essas manifestações, ao serem consideradas como normais, constituem índices de evolução psíquica na medida em que denotam tentativas e possibilidades de a criança se confrontar com ansiedades e frustrações da vida de relação; ou seja, denotam possibilidade de se confrontar ao mesmo tempo que lidar com ansiedades e frustrações em relação à própria experiência de sono caracterizada por separação do mundo circunstante a par da vivência de imagens de tipo onírico.

A intensidade na manifestação dos índices citados, seja na sua frequência, seja na sua qualidade emotiva, pode reverter em impedimento no estabelecimento e na manutenção do sono; distúrbios como insónia (dificuldade em adormecer, despertares notumos com experiência de susto e terror), terrores notamos, pesadelos constantes e/ ou repetitivos, constituem sinàis de conflitos emocionais que a criança enfrenta com dificuldade nos níveis cognitivo, afetivo e social.

Em adição a esses dados, deve-se atualmente levar em conta as contribuições da cronobiologia que nos permitem também avaliar diferenças individuais e circunstanciais entre os individuos do mesmo grupo. Considerando-se padrões de sono no que respeita a duração e horário no período de 24 horas, podem-se citar os grandes e os pequenas dormidores, assim como sujeitos matutinos e vespertinos. Da mesma forma, podem-se indicar distúrbios de sono devidos aos efeitos de condições ambientais como no caso de viagens internacionais, turnos noturnos de trabalho em periodos diversos, etc. citados em adultos (CIPOLLA-NETO et ai, 1990).

Os diferentes distúrbios exigirão por parte da mãe, mas também daqueles que participam do ambiente da criança, medidas no sentido de favorecer condições ambientais tranquilizadoras e adequadas à instalação e manutenção do sono. Especialmente no sentido de evitar que se crie um círculo vicioso diante das dificuldades vividas e das exigências impostas pela criança aos outros membros do grupo: o esgotamento, muito especialmente nos responsáveis, (noites maldormidas, irritação, incapacidade de resolver a situação por parte dos pais) pode vir a ser uma constante a se somar aos encargos diurnos, ou a dificultar a execução das medidas necessárias para garantir o estabelecimento do sono na criança.

A partir dos 7 anos, pode-se observar uma organização dada pela própria criança, ou seja, a configuração de comportamentos específicos favorecendo a indução de sono. No período de 7 a 12 anos, o comportamento de dormir pode vir a colocar menos problemas que no período de 2 a 6-7 anos.

\section{CARACTERIZA,CÃO DOS SUJEITOS}

As informações que constituem os dados levantados e apresentados nas tabelas a seguir foram obtidas junto a mães de 30 crianças, sexo masculino e feminino, que frequentam a pré-escola (exceção de uma menina de 2a. llm.) em estabelecimento de clientela de nível sócioecon8mico médio. A grande maioria dos pais (25 mães e 23 pais) tem instrução universitária.

As crianças estão distribuídas em dois grupos de 15 sujeitos. No primeiro grupo, encontramse crianças de 2 a. $6 \mathrm{~m}$. a3 a. $8 \mathrm{~m}$.. No segundo, crianças de4a. $6 \mathrm{~m}$. a 5 a. 6 m..

Mantém-se bastante semelhante a distribuição quanto a sexo: 15 do sexo masculino, 15 do sexo ferninino, 8 e 7 respectivamente no Grupo 1, 7 e 8 no Grupo 2. Mantém-se semelhante a distribuição nas classes de Maternal e Jardim de Infancia: 8 meninos e 6 meninas no primeiro, 7 meninos e 8 meninas no segundo.

TABELA I - Número de sujeitos por idade, sexo, escolaridade

\begin{tabular}{|c|c|c|c|c|c|c|c|}
\hline \multirow[t]{2}{*}{ Sujeitos } & \multirow[t]{2}{*}{ Itade } & \multicolumn{2}{|c|}{ Sexo } & \multicolumn{3}{|c|}{ Escotaridade } & \multirow[t]{2}{*}{ Totais } \\
\hline & & Masc. & Fem. & Maternal & Jardim & A traq. & \\
\hline \multirow[t]{2}{*}{ Grupo I } & $2 a 6 m-3 a 0 m$ & DI & 03 & - & - & - & - \\
\hline & $32.0 \mathrm{~m}-3.4 .8 m$ & or & 04 & 14 & - & 01 & 15 \\
\hline \multicolumn{2}{|r|}{ Totais } & 08 & $m$ & 14 & - & 01 & 15 \\
\hline \multirow[t]{2}{*}{ Ginpo 2} & $4 a 6 m \cdot 5 a 0 m$ & 05 & 04 & - & - & - & - \\
\hline & $5 a 0 m-5 a \in m$ & 62 & 04 & - & is & - & is \\
\hline \multicolumn{2}{|r|}{ Totais } & o7 & 08 & - & 15 & - & 19 \\
\hline
\end{tabular}

\section{PROCEDIMENTO}

A metodologia utilizada foi a aplicação de questionário construído por questões abertas e questões de múltipla escolha, versando sobre horários, hábitos, temores, rituais, etc., relacionados com o sono e o sonho da criança e respondidos pelas mães. Alguns destes questionários, quando necessário para maior esclarecimento, foram complementados por entrevistas.

Privilegiamos, nesta apresentação, os dados obtidas tais como se encontram nas tabelas referidas à apresentação e discussão dos resultados como se seguem. 


\section{RESULTADOS E DISCUSSÃO}

Especializando o tratamento dos aspectos de ordem psicossocial como prováveis configuradores na evolução do padrão de comportamentos de sono nas crianças mencionadas, nossa apresentação de dados levará em conta os pontos seguintes:

- Sesta, ou seja, o sono durante a tarde. Horário de dormir.

- Hábitos ligados ao adormecer e à manutenção do sono. - Demonstraçao de medo do escuro. - Ocorrência de sonho.

\section{Sesta, ou seja, o sono durante a tarde}

Mais da metade das crianças menores (de 2a. $6 \mathrm{~m}$. a 3a. $6 \mathrm{~m}$.) e a grande maioria das crianças de 4 a. 6 m. a 5 a. m. não mantêm a sesta. Os dados colhidos pelos questionários e pelas entrevistas indicam que a maioria das crianças no grupo estudado abandonou o sono diurno entre I a. 6 m. e 2 anos (6), e especialmente entre 2 e 3 anos (lü entre 2a. e 2a. 6m.; 7 entre 2a. 6m. e 3a.), diferentemente dos dados citados na literatura. GESELL ( 1956) e mais tarde HUON ( 1972), por exemplo, indicam a idade ao redor de 4 anos. Vale notar que as meninas em maior número, mais cedo: 4 de la. $6 \mathrm{~m}$. a 2a, 6 de 2a. a 2a. $6 \mathrm{~m}$. .

TABELA II - Abandono da sesta em relação à entrada na escola, por idade e sexo

\begin{tabular}{|c|c|c|c|c|c|}
\hline \multirow{2}{*}{ Idade Sexo } & \multicolumn{2}{|c|}{$\begin{array}{c}\text { Entrada na } \\
\text { Escola }\end{array}$} & \multicolumn{2}{|c|}{$\begin{array}{c}\text { Abandono } \\
\text { "Espontâneo" }\end{array}$} & \multirow{2}{*}{ Total } \\
\hline & Masc. & Fem. & Masc. & Fem. & \\
\hline $1 \mathrm{a} .6 \mathrm{~m} .-2 \mathrm{a} .0 \mathrm{~m}$. & - & 02 & 01 & 02 & 05 \\
\hline $2 \mathrm{a} .0 \mathrm{~m} .-2 \mathrm{a} \cdot 6 \mathrm{~m}$ & 03 & 03 & 01 & 03 & 10 \\
\hline $2 \mathrm{a} .6 \mathrm{~m} .-3 \mathrm{a} .0 \mathrm{~m}$. & 02 & 01 & 03 & 01 & 07 \\
\hline $3 \mathrm{a} .0 \mathrm{~m} .-3 \mathrm{a} \cdot 6 \mathrm{~m}$ & 01 & - & - & - & 01 \\
\hline $3 \mathrm{a} .6 \mathrm{~m} .-4 \mathrm{a} .0 \mathrm{~m}$ & 01 & 01 & - & - & 02 \\
\hline $4 a .0 m-4 a \cdot 6 m$ & - & 01 & 01 & - & 02 \\
\hline TOTAL & 07 & 08 & 06 & 06 & $27^{*}$ \\
\hline
\end{tabular}

* 3 meninas mantêm a sesta (2a. 8m.; 3a. 4m.; 4a. 11m.)
Algumas considerações parecem tornar-se válidas a respeito. Poderíamos considerar a idade precoce em que as crianças atualmente começam a frequentar a pré-escola, como determinante na interrupção da sesta, dessa forma, portanto, interferindo sobre seu padrão de sono e determinando o abandono mais precoce desse período de sono diurno. Acresce o falo que a entrada da criança na pré-escola está muitas vezes condicionada ao horário de trabalho da mãe, seja por necessidade económica, seja por realização pessoal desta última.

No entanto, levando-se em conta que metade das crianças que apresentaram esse comportamento entre 2 e 3 anos, fizeram-no espontaneamente, pode-se aventar a hipótese contrária como verdadeira: ou seja, o falo de ser colocada a frequentar mais cedo a escola seja favorecido justamente porque a criança apresente abandono da sesta e permaneça desperta por maior quantidade de tempo durante o período diurno. Segundo WEBB (1969), por exemplo, há dados para se supor que as crianças estariam dormindo menos, atualrnente.

Uma observação faz-se necessária. Pelas respostas obtidas das mães, percebe-se que para as crianças do Grupo 2, as idades de abandono da sesta sôo mais tardias, assim como sua entrada na escola. Esses dados estariam apontando para uma diferenciação no grupo tomado como um todo, nas faixas de idade diversa, devido provavelmente a variaveis não pesquisadas. Ou poderia-se falar da relatividade nas respostas obtidas por questionário num espaço de tempo dilatado entre as mães do Grupo 2 em relação às mães do Grupo 1: efeitos de fatores intervindo na possibilidade de recordação mais ver dica dos falos sendo os responsáveis por distorção dos resultados. Por outro lado, se as crianças entraram em idade mais avançada na escola, talvez estariam as relações de tempo citadas determinadas por ritmos característicos nos grupos familiares de origem: ritmos no padrão sono-vigília, ritmos no cumprimento de exigencias educacionais, etc...

\section{Horário de dormir}

O horário de dormir apresenta variação de 19:00 a 23:00 horas, mesmo nas faixas de idade mais precoces. Ainda hoje pode-se certannente considerar elevado o número de crianças que se deita entre 21:00 e 23:00 horas nas faixas de idade que compõem o Grupo 1; o mesmo se diria a respeito do Grupo 2. Especialmente levando em consideração o que se poderia esperar diante de estratégias educacionais vigorando até há bem pouco tempo. $\mathrm{O}$ falo surpreende especialmente por já não apresentar na época, a maioria das crianças, 0 sono diurno. 
A organização de padrões de ritmo como caracterizam os sujeitos vespertinos e matutinos, poderia estar subjazendo a esse comportamento de sono. Observações espec $\sim \wedge$ lcas poderiam favorecer conclusões a esse respeito, levantando dados durante o período anterior, e inclusive no período posterior de desenvolvimento destas crianças.

Podemos confirmar, pelo momento, possíveis efeitos de atitude flexível ou até permissiva dos pais em relação ao horário de dormir de seus filhos. Alguns relatos parecem sugerir que o falo de ambos os pais trabalharem fora e permanecerem grande parte do dia afastados de seus filhos explica a tendência de permitirem que a criança se dirija para a cama e durma em horário mais avançado, no intuito de compartilharem algum tempo com ela; sugarem também dificuldade em impor limites, gerada por culpa face a sua ausência prolongada, privando a criança de seus cuidados.

Acresce o falo de a televisão exercer expressiva interferência nos costumes familiares atuais, condicionando não apenas os adultos, mas também as crianças, a postergarem o início de seu sono. Dessa forma, tanto num como noutro caso, referimos a interveniência de fatores de ordem educacional, afetiva e sócio-cultural.
A escolha do horário de dormir prevalentemente pela criança já no Grupo 1 (13 crianças no Grupo I e 9 crianças no Grupo 2) e não pelos pais, estaria no sentido indicado pelas explicações anteriores em relação ao horário de dormir.

Hábitos ligados ao adormecer e à manutenção do sono

Entre os hábitos estabelecidos na criança constituindo seu comportamento no momento de adormecer e em vista de manter o sono, destacamos: a necessidade de acompanhamento para se dirigir para a cama, a escolha de local para adormecer, a solicitação de estarias para dormir, a utilização de objeto transicional.

Praticamente metade das crianças de 4 a. $6 \mathrm{~m}$. a 5 a. $6 \mathrm{~m}$. de idade dirige-se sozinha para a cama para dormir. Na maioria do grupo, como um todo, ainda que possuam habilidades mataras e cognitivas para tal, as crian,cas não o fazem; manifestam relutancia a se desligar dos pais, mostrando-se dependentes destes sem condições de procurar espontaneamente 0 quarto para dormir. Esse falo estaria a indicar a necessidade de garantir a companhia e a presença dos mesmos para adormecer e manter o sono durante a noite.

TABELA III - Horário de dormir, por idade e sexo

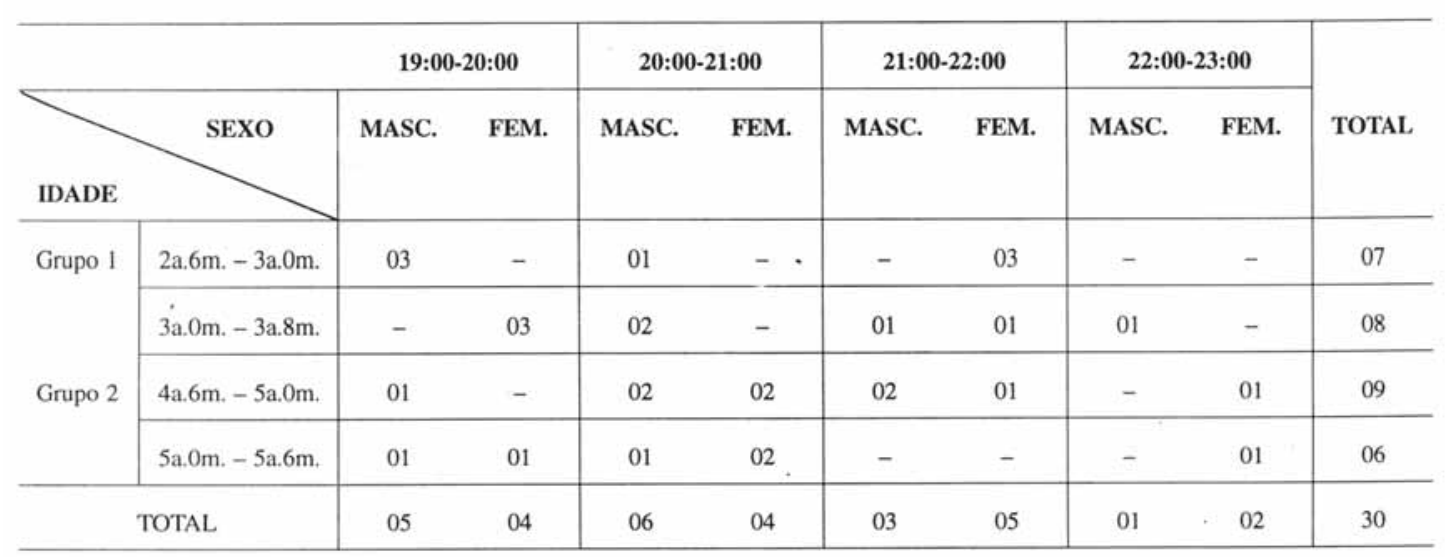

Na realidade, em torno da metade das crianças não adormece sempre naprópria cama. Os locais mais citados são a sala de TV e a cama dos pais. Em alguns casos (6 meninos e 2 meninas) as crianças adormecem na sala de TV, na própria cama, ou na cama dos pais. Nas faixas etárias referidas tanto no Grupo 1 como no Grupo 2, as 
crianças não dormem embaladas e no colo, mas provavelmente procuram prolongar a relação com o ambiente, os familiares e especialmente os pais (todos muitas vezes catalisados pela TV) antes de dormir, garantindo condições de segurança nesse momento.

O dormir e o sono têm sido comumente considerados como correlatos à separação, ruptura, morte. Nesse sentido tem sido indicada a angústia de separação, vivida pela criança, como estando na base dessas manifestações que por vezes revelam o caráter fóbico e o caráter contrafóbico citados acima.

Pedir ao adulto que Ihes conte estarias antes de dormir é um hábito que atinge 50\% das crianças, embora os pedidos não ocorram com a mesma frequência considerando-se cada uma delas. Ter seu pedido satisfeito garante a presença da mãe, estimula a própria fantasia e cria condições para a repetição de experiências prazeirosas. Por outro lado, favorece a passagem a um estado endereçando ao sono.

TABELA IV - Solicitação de estórias para dormir*, por idade e sexo

\begin{tabular}{c|c|cc|c}
\hline \multicolumn{2}{c|}{ SEXO } & MASC. & FEM. & TOTAL \\
\hline \multirow{2}{*}{ IDADE } & & & \\
\hline \multirow{2}{*}{ Grupo 1 } & $2 \mathrm{a} .6 \mathrm{~m} .-3 \mathrm{a} .0 \mathrm{~m}$. & 01 & 01 & 02 \\
\cline { 2 - 5 } & $3 \mathrm{a} .0 \mathrm{~m} .-3 \mathrm{a} .8 \mathrm{~m}$. & 02 & 01 & 03 \\
\hline \multirow{2}{*}{ Grupo 2 } & $4 \mathrm{a} .6 \mathrm{~m} .-5 \mathrm{a} .0 \mathrm{~m}$. & 04 & 03 & 07 \\
\cline { 2 - 5 } & $5 \mathrm{a} .0 \mathrm{~m} .-5 \mathrm{a} .6 \mathrm{~m}$. & 01 & 02 & 03 \\
\hline \multicolumn{2}{c}{ TOTAL } & 08 & 07 & 15 \\
\hline
\end{tabular}

*Apenas duas crianças (uma do sexo feminino, 2a. $9 \mathrm{~m}$. e uma do sexo masculino, 2a. $8 \mathrm{~m}$.) solicitam estórias todas as noites.

Na criança maior, a estaria poderá se constituir como um substitutivo do acalanto, das cantigas de ninar, que reasseguram a proximidade materna e suas demonstrações de afeto; pelo conteúdo terrorífico de muitas das estórias, estas têm também um papel de interpor a lei e estabelecer o terreno do proibido com que a criança se defronta igualmente.
TABELA V - Uso de objeto transicional, por idade e sexo

\begin{tabular}{c|c|cc|c}
\hline \multicolumn{2}{c|}{ SEXO } & MASC. & FEM. & TOTAL \\
\multicolumn{2}{c|}{ IDADE } & & & \\
\hline \multirow{2}{*}{ Grupo 1 } & $2 \mathrm{a} .6 \mathrm{~m} .-3 \mathrm{a} .0 \mathrm{~m}$. & 01 & 03 & 04 \\
\cline { 2 - 5 } & 3a.0m. $-3 \mathrm{a} .8 \mathrm{~m}$. & 07 & 04 & 11 \\
\hline \multirow{2}{*}{ Grupo 2 } & $4 \mathrm{a} \cdot 6 \mathrm{~m} .-5 \mathrm{a} .0 \mathrm{~m}$. & 02 & 03 & 05 \\
\cline { 2 - 5 } & $5 \mathrm{a} .0 \mathrm{~m} .-5 \mathrm{a} .6 \mathrm{~m}$. & - & 02 & 02 \\
\hline & TOTAL & 10 & 12 & 22 \\
\hline
\end{tabular}

Um dado chama atenção pela universalidade: $\mathrm{d}$ todas as crianças, meninos e meninas, apenas uma na utilizou durante algum tempo um objeto específico par conciliar o sono. Incluemse bico e mamadeira, na cas referente a chupeta, mas em mínima proporção em reli ção a esta última; o mesmo ocorre com fralda, fronha lençol que se incluem na casa referente a cobertor.

Na sua totalidade, as crianças de 2 a. $6 \mathrm{~m}$. a 3a. $6 \mathrm{~m}$ utilizam um e mesmo objeto, enquanto que entr as crianças de 4 a. 6 m. a Sa. 6 m., menos da metad o faz. No grupo como um todo, entre meninos e men nas, maior utilização se faz da chupeta e objetos d semelhante função especialmente no Grupo 1; em sã gundo lugar, do cobertor (e semelhantes), - Objetc como bichos e bonecos aparecem mais especialmente em momento posterior.

Comparando-se o primeiro com o segundo grupo observa-se abandono progressivo com o avanço na idade A importância deste objeto foi pela primeira vez, e exale tivamente, indicada por VVINNICOTI (1978) que denominou objeto transicional. Constitui algo de impo tancia vital na hora de ir para a cama dormir, como urr espécie de defesa em relação à ansiedade, especialmente a de tipo depressivo. E pertinente aqui lembrar como costume popular dá acesso ao uso pela criança de objet tidas, afinal, como facilitadores da passagem ao sono: o caso, por exemplo, do pedaço de cobertor, ou da frald ou do travesseirinho que se carrega por algum tempo, i vezes anos, representantes da relação com a mãe, Faraó findo a subsistência da criança, na medida em que adqui^] o estatuto de parte constituinte sua, da qual não pode separar. 
Gradativamente descateizado à medida que a criança cresce, esse objeto não é alvo de repressão, apenas perde seu significado quando se ampliam suas capaci a a de elaboração como se encontram no brinquedo, na criatividade artística e no sonho.

\section{Demonstração de medo do escuro}

TABELA VI - Medo do escuro, por idade e sexo

\begin{tabular}{|c|c|c|c|c|}
\hline \multicolumn{2}{|c|}{ IDADE } & MASC. & FEM. & TOTAL \\
\hline \multirow[t]{2}{*}{ Grupo 1} & $2 \mathrm{a} .6 \mathrm{~m} .-3 \mathrm{a} .0 \mathrm{~m}$ & - & 01 & 01 \\
\hline & 3a. $0 \mathrm{~m} .-3 \mathrm{a} .8 \mathrm{~m}$. & 01 & - & 01 \\
\hline \multirow[t]{2}{*}{ Grupo 2} & 4a.6m. $-5 \mathrm{a} .0 \mathrm{~m}$ & 03 & 03 & 06 \\
\hline & 5a.0m. $-5 \mathrm{a} .6 \mathrm{~m}$. & 02 & 02 & 04 \\
\hline \multicolumn{2}{|r|}{ TOTAL } & 06 & 06 & 12 \\
\hline
\end{tabular}

Em relação à necessidade da criança de dormir com a luz acesa, os dados sao aparentemente contra itór os. No grupo das crianças entre 2 e 3 a. m., apenas 3 (1 menino na faixa de 2a. $6 \mathrm{~m}$. a 3a., $\sim$ menino e $\sim$ menina na faixa posterior) não dormem no escuro. inversamente a grande maioria das crianças entre 4 e 5 a. (9) e entre $\mathrm{S}$ a. e 5 a. 6 m. (4) solicita insistentemente a luz acesa.

Para BATES AMES 1964 o medo do escuro acentua-se ou inicia-se ao redor dos 3 a. 6 m., per uran 0 até aos 5 anos; esse medo referese a figuras de animais, fantasmas ou personagens terroríficos. Essas representações de tipo onírico são muito possivelmente remanescentes de imagens experimentadas pela criança ao adormecer e em sonhos, dos quais acorda em sobressalto durante a noite, muitas vezes chorando e gritando.

Constituindo verdadeiras fobias, o medo do escuro pode ser explicado pelo deslocamento de medos internos para perigos extemos. Pela teoria psicanalítica, nesta fase a angustia estará relacionada ao temor de castração e ao complexo edipico, etapa considerada como crucia no desenvolvimento psico-afetivo entre 3 e 6 anos.
Keav $\sim$ vando-se a ansiedade no momento da passagem ao adormecimento, quando ocorre um desligamento sucessivo das relações com o mundo circunstante, e especia mente a suposta perda da segurança of erecida pelos adultos, sobretudo dos pais, a criança passa a se utilizar de condutas contrafóbicas MAZET \& BRACONNIER, 1986): solicita, entao, a luz acesa, a porta aberta, exige a presença da mãe e/ou do pai e de irmãos, abraça-se a objetos contrafóbicos Como os transicionais , ou a ormece na cama dos pais.

Entre as crianças estudadas, observa-se um movimento nesse sentido, especialmente a partir da idade de 3 anos, e muito especialmente na idade de 4 a. $6 \mathrm{~m}$. a 5 anos, recrudescendo posteriormente, não sendo, no entanto, manifestação do grupo como um todo.

\section{Ocorrência de sonho}

A maioria das mães das crianças entre 2 e 3 ar^los, quando solicitadas a respeito da capacidade de a criança distinguir entre o sonho e outros fenómenos como o devaneio e a fantasia, responde que seus filhos não sabem diferenciar o sonho como tal; ou indicam ter dúvidas sobre sua capacidade de reconhecimento do que seja sonho. Quanto às crianças de mais de 4 anosa metade das mães informa que sabem discriminar o sonho.

TABELA VII - Relato de sonhos, por idade e sexo*

\begin{tabular}{|c|c|c|c|c|}
\hline \multicolumn{2}{|c|}{ IDADE } & MASC. & FEM. & TOTAL \\
\hline \multirow[t]{2}{*}{ Grupo 1} & $2 \mathrm{a} \cdot 6 \mathrm{~m} .-3 \mathrm{a} .0 \mathrm{~m}$ & - & 01 & 01 \\
\hline & 3a.0m. - 3a.8m. & 04 & - & 04 \\
\hline \multirow[t]{2}{*}{ Grupo 2} & $4 \mathrm{a} .6 \mathrm{~m} .-5 \mathrm{a} .0 \mathrm{~m}$ & 03 & 03 & 06 \\
\hline & $5 \mathrm{a} .0 \mathrm{~m} .-5 \mathrm{a} .6 \mathrm{~m}$ & 01 & 01 & 02 \\
\hline \multicolumn{2}{|c|}{ TOTAL } & 08 & 05 & 13 \\
\hline
\end{tabular}

* Não se obteve resposta para 2 crianças ( 1 menino e 1 menina do Grupo 2) 
Em relação ao relato dos sonhos, percebese que o número total dobra no segundo grupo, ou seja, aproximadamente metade das crianças de mais de 4 anos o faz regular ou esporadicamente, seguindo uma tendência semelhante à apontada no tópico anterior. No que se refere aos conteúdos oníricos, este estudo aponta para uma nítida diferença entre crianças em idade de 2 a 3 anos e crianças em idade de 4 a 5 anos.

As primeiras, entre as meninas, apenas mencionam temas através de imagens, como cavalinhos, bichinhos, amiguinhos, Papai Noel e Papai Noel que “deixou presente para mim”. As demais meninas no Grupo 1 não apresentam relato de sonho. Entre os meninos, de certa forma o falo inverte-se. É a partir de 3 anos até 3 a. 8 m. que são relatados sonhos. Diferentemente dos citados nas meninas, apresentam sinais de conflito: sonho em que está brigando com o irmão; sonho com animais, cães e gatos, girafa; sonho com o homem do saco que quer pegar o sonhador; sonho com princesa e bruxa.

No segundo grupo, as crianças relatam uma história, nesse sentido, aproximando-se do relato de sonho no adulto. Apresentam, entre as meninas, conteúdos relacionados diretamente a conteúdos realistas do período da vida de vigília, como: encontro com parentes; desenho de coração como presente para a mãe pelo que a criança ganha um beijo desta última; boneca a par de pe-

\section{BIBLIOGRAFIA}

BATES AMES, L. Sleep and dreams in childhood. In: HARMS. Problerns of sieep anti dream in chfidren. Oxford, Pergamon Press, 1964.

CIPPOLA-NETO, J.; MENNA-BARRETO, L.; MARQUES, N.; AFECHE, S. C.; SILVA, A. A. B. Cronobiologia do ciclo vigfliasono. In: REIMÃO, R. Sono: aspectos atuais. São Paulo, Ed. Atheneu, 1990.

GESELL, A. El niño de uno a cinco anos: guia para el estudio del niño preescolar. Buenos Aires, Paidós, 1956.

HUON, H. Physiologie du sommeil de l'enfant. Rev. Neuropsych Inf., 20(11-12): 815-827, 1972.

HOUZEL, D. Fonction du rêve et psychopathologie du sommeil de l'enfant. Rev. Neuropsychiat. Inf., 20: 829-838, 1972. sadelos e atropelamento. Quanto aos meninos do segundo grupo: sonho com o presente que quebrou; com a mãe que apertou botão que não sabia para que servia e destruiu coisas; desenhos de TV.

Em um como noutro grupo os sonhos parecem estar servindo e representando conteúdos simbolicamente significativos do conflito, assim como métodos para lidar com angústias de diversas ordens.

\section{CONSIDERAÇÕES FINAIS}

Esta pesquisa inicial nos traz indicativos de interesse acerca do padrão de sono em crianças de 2 a. 6 m. a 5 a. 6 m.. Alguns dados corroboram os existentes na literatura, como, por exemplo, a utilização frequente de um objeto para adormeceria instalação do medo ao escuro, a idade em que surge o relato de sonhos. Alguns apresentam uma sensível discrepância em relação a dados de fontes diversas, como o abandono da sesta e o horário de dorrnir.

A limitação das observações e das possibilidades de análise devido ao pequeno número de grupos, e de sujeitos em cada grupo, não impede de perceber que, no mínimo, os dados permanecem instigantes quanto à possibilidade de fornecer subsídios à construção de conhecimento sobre o sono nacriançae nas diversas fases de seu desenvolvimento.

MAZET, P.; BRACONNIER, A. Le sornmeil de l'enfant et ses troubies. Paris, PUF, 1986.

SALZARULO, P.; CHEVALIER, A.; COLVEZ, A.; BRUNEL, M.; SENDER, C.; KASTLER, B.; ROC, M. Child sleep problems. Parental attitude and recourse: an approach by survey. Sleep, Fourth European Congress on Sieep Research, 595-598, 1978.

SALZARULO, R; CHEVALIER, A. Sleep problems in children and their relationship with early disturbance of the waking-sleeping rhythms. Sleep, 6(1):47-51, 1983.

WEBB, W. B. Twenty-four-hour sleep cycling. In: KALES, A. Sleep physioiogy and pathoiogy. USA, Lippicot, 1969.

WINNICOIT, D. W. Da pediatria à psicanfiiise. Rio de Janeiro, Ed. Francisco Alves, 1978.

recebido em: 20/04/95 aprovado em: 26/07/95 